\title{
Prediction of Neonatal Hyperbilirubinemia Using 1st Day Serum Bilirubin Levels: Correspondence
}

Received: 18 March 2019 / Accepted: 14 June 2019/Published online: 11 July 2019

(C) Dr. K C Chaudhuri Foundation 2019

To the Editor: We have read with great interest the article on prediction of neonatal hyperbilirubinemia using first day serum bilirubin levels published in Indian Journal of Pediatrics [1]. Neonatal hyperbilirubinemia has significant burden in low and middle income countries, leading to morbidity and mortality [2]. As a result, screening strategies need to be devised addressing problems specific to these countries. We have two comments on this well conducted study.

Bhutani et al., in 1999, have published predictive ability of hour-specific predischarge serum bilirubin levels in predicting subsequent hyperbilirubinemia [3]. This large study, based on 2976 neonates, has given predictive nomograms. At $24 \mathrm{~h}$, a bilirubin value below $5.0 \mathrm{mg} / \mathrm{dl}$ indicates the low-risk zone where no neonates develop significant hyperbilirubinemia. Similarly, below a bilirubin level of $6.5 \mathrm{mg} / \mathrm{dl}$ (approximately), $7.4 \%$ neonates develop significant hyperbilirubinemia. The results of the current study are no different from these results.

In this study, it was concluded that a cut-off of $6.15 \mathrm{mg} / \mathrm{dl}$ would predict low risk of significant hyperbilirubinemia. But, it has a sensitivity of only $82.4 \%$ and negative predictive value of $97.6 \%$, meaning $17.6 \%$ neonates will still develop significant hyperbilirubinemia. Instead, we can chose a cut-off with sensitivity $>95 \%$ from the ROC curve. This will make the chance of missing a case of significant hyperbilirubinemia negligible.

\section{Rajendra Prasad Anne ${ }^{1}$ and Emine A Rahiman ${ }^{2}$}

Department of ${ }^{1}$ Neonatology and ${ }^{2}$ Pediatrics, Post Graduate Institute of Medical Education and Research, Chandigarh, India. E-mail: rajendra.omc@gmail.com

\section{References}

1. Spoorthi SM, Dandinavar SF, Ratageri VH, Wari PK. Prediction of neonatal hyperbilirubinemia using 1st day serum bilirubin levels. Indian J Pediatr. 2019;86:174-6.

2. Olusanya BO, Ogunlesi TA, Slusher TM. Why is kernicterus still a major cause of death and disability in low-income and middle-income countries? Arch Dis Child. 2014;99:1117-21.
3. Bhutani VK, Johnson L, Sivieri EM. Predictive ability of a predischarge hour-specific serum bilirubin for subsequent significant hyperbilirubinemia in healthy term and near-term newborns. Pediatrics. 1999;103:6-14.

\section{Author's Reply}

To the Editor: We thank the authors for reading our article entitled "Prediction of neonatal hyperbilirubinemia using $1^{\text {st }}$ day serum bilirubin levels" published in IJP [1]. We appreciate their valuable comments. They have rightly said that an ideal cut-off value which is on the lower side will be good for screening purpose and will have higher sensitivity of more than $95 \%$. But in our study [1], we have arrived at a cut-off value based on ROC curve obtained. Choosing a lower cut-off value nearer to $5 \mathrm{mg} / \mathrm{dl} \mathrm{re-}$ sulted in higher sensitivity but at the cost of specificity and it went down drastically. An ideal test should have $100 \%$ sensitivity and $100 \%$ specificity which is practically very difficult [2]. So we chose the cut-off value to balance both sensitivity and specificity, keeping both above $80 \%$ which gave us higher negative predictive value. Similar study if done in a large sample can show us a better picture and as highlighted by the authors, can give an idealistic cut-off value with sensitivity more than $95 \%$ as well.

\section{S. M. Spoorthi ${ }^{1,2}$}

Department of Pediatrics, ${ }^{1}$ Karnataka Institute of Medical Sciences, Hubballi, Karnataka, and ${ }^{2} J J M M C$, Davanagere, India. E-mail: spoorthi89.sm@gmail.com

\section{References}

1. Spoorthi SM, Dandinavar SF, Ratageri VH, Wari PK. Prediction of neonatal hyperbilirubinemia using 1st day serum bilirubin levels. Indian J Pediatr. 2019;86:174-6.

2. Park K. Park's Textbook of Preventive and Social Medicine, 23rd ed. 2015. p. 135-40.

Publisher's Note Springer Nature remains neutral with regard to jurisdictional claims in published maps and institutional affiliations. 